\title{
GT2004-53485
}

\section{A PROBABILISTIC ASSESSMENT OF NASA ULTRA-EFFICIENT ENGINE TECHNOLOGIES FOR A LARGE SUBSONIC TRANSPORT}

\author{
Michael T. Tong and Scott M. Jones \\ National Aeronautics and Space Administration \\ Glenn Research Center \\ Cleveland, Ohio 44135
}

\author{
Philip C. Arcara, Jr. \\ National Aeronautics and Space Administration \\ Langley Research Center \\ Hampton, Virginia 23681
}

\author{
William J. Haller \\ National Aeronautics and Space Administration \\ Glenn Research Center \\ Cleveland, Ohio 44135
}

\begin{abstract}
NASA's Ultra Efficient Engine Technology (UEET) program features advanced aeropropulsion technologies that include highly loaded turbomachinery, an advanced low- $\mathrm{NO}_{\mathrm{x}}$ combustor, high-temperature materials, intelligent propulsion controls, aspirated seal technology, and an advanced computational fluid dynamics (CFD) design tool to help reduce airplane drag. A probabilistic system assessment is performed to evaluate the impact of these technologies on aircraft fuel burn and $\mathrm{NO}_{\mathrm{x}}$ reductions. A 300-passenger aircraft, with two $396-\mathrm{kN}$ thrust (85,000-pound) engines is chosen for the study. The results show that a large subsonic aircraft equipped with the UEET technologies has a very high probability of meeting the UEET Program goals for fuel-burn (or equivalent $\mathrm{CO}_{2}$ ) reduction $(-15 \%$ from the baseline) and LTO (landing and takeoff) $\mathrm{NO}_{\mathrm{x}}$ reductions $(-70 \%$ relative to the 1996 International Civil Aviation Organization rule). These results are used to provide guidance for developing a robust UEET technology portfolio, and to prioritize the most promising technologies required to achieve UEET program goals for the fuel-burn and $\mathrm{NO}_{\mathrm{x}}$ reductions.
\end{abstract}

Keywords: NASA, ultra-efficient engine technologies, probabilistic, propulsion system analysis, fuel burn, $\mathrm{CO}_{2}, \mathrm{LTO}$ $N O_{x}$

\section{INTRODUCTION}

Throughout the past century, propulsion innovations were the driving force behind the evolution of air transportation. Advances in propulsion system technology offer the greatest single contribution to the improvement of fuel economy, capacity, and the environmental impact of commercial aircraft.

In the twenty-first century, propulsion will continue to be the enabling technology to revolutionize air transportation. To maintain the superiority of U.S. aerospace industry into the $21 \mathrm{st}$ century, and to assist in meeting public demand for safety, reliability, environmental compatibility, and affordability, NASA initiated the Ultra-Efficient Engine Technology (UEET) program in year 2000.

NASA's UEET program is designed to revolutionize the state of the art in propulsion and propulsion/airframe integration technologies with specific objectives to reduce aircraft fuel burn (or $\mathrm{CO}_{2}$ ) and $\mathrm{NO}_{\mathrm{x}}$, relative to current engines. It features advanced technologies that include:

$\underline{\text { Tech ID }}$

tech-1

tech-2

tech-3

tech-4

tech-5

tech-6

tech-7

tech-8

tech-9

tech-10

tech-11

tech-12
Technology name advanced low $\mathrm{NO}_{\mathrm{x}}$ combustor highly loaded compressor technology highly loaded turbine systems $1482^{\circ} \mathrm{C}\left(2700^{\circ} \mathrm{F}\right)$ ceramic matrix composite (CMC) turbine vane $1482{ }^{\circ} \mathrm{C}\left(2700^{\circ} \mathrm{F}\right) \mathrm{CMC}$ combustor liner advanced compressor disk alloy low conductivity ceramic thermal barrier coating (TBC) for turbine airfoils advanced airfoil alloy development high Reynolds number (advanced CFD) design tool for advanced configuration rotating machinery clearance management high temperature wireless data communication aspirating seal 
The NASA UEET Program goals are a $70 \%$ reduction in landing and take-off (LTO) $\mathrm{NO}_{\mathrm{x}}$ relative to the 1996 International Civil Aviation Organization (ICAO) standard and a 15\% fuel-burn improvement relative to the current state of the art large subsonic transports.

A probabilistic system assessment is performed to evaluate the impact of these technologies on aircraft fuel-burn and $\mathrm{NO}_{\mathrm{x}}$ reductions. The statistical approach quantifies the uncertainties inherent in these new propulsion technologies and their influence on the likely outcomes of engine performance. Consequently, it provides additional insight into the risks associated with new technologies, which are often needed by the decision-makers to determine the benefit and return-oninvestment of new propulsion technologies. The results are used to provide guidance for the development of a robust UEET technology portfolio, and to prioritize the most promising technologies required to achieve UEET program goals for the fuel-burn and $\mathrm{NO}_{\mathrm{x}}$ reductions.

\section{ANALYSIS APPROACH AND PROCEDURES}

\section{Expert Opinion Elicitation}

As Rand analyst E.S. Quade observed about 30 years ago, "Intuition and judgment permeate all analysis ... As questions get broader, intuition and judgment must supplement quantitative analysis to an increasing extent" [1]. Expert judgment must be used to judge the risks of emerging technology. Obtaining and quantifying input data is probably the most crucial part of performing risk assessments. It is a crucial but generally overlooked issue [2]. As such, it deserves detailed attention.

For the current assessment, a technology audit scheme (TAS) developed by Kirby and Mavris [3] is used to elicit opinions from the NASA technologists identified as the focal point for each of the UEET technologies. The scheme is based on the Delphi method [4], which is a structured process for collecting and distilling knowledge from a group of experts by means of a series of questionnaires and interviews interspersed with controlled opinion feedback. The focus of the TAS is to identify the applicable set of UEET technologies for the vehicle of interest, gather the required information, and compile the data necessary for the system analysis. The process is described in detail in reference [5].

\section{The Beta Distribution}

Based on the information obtained from the technologists, the 3-point estimates (maximum, minimum, and most-likely values) of the impacts (positive and/or negative) for each of the technologies are quantified. They are summarized in Table 1. A four-parameter beta distribution is then created for each of the technologies. The probability density function (PDF) of the beta distribution is

$$
f(x)=\frac{1}{B(p, q)} \frac{(x-a)^{p-1}(b-x)^{q-1}}{(b-a)^{p+q-1}}
$$

and the cumulative density function (CDF) is

$$
C D F(t)=\frac{1}{B(p, q)} \int_{0}^{t} t^{p-1}(1-t)^{q-1} d t
$$

with the transformation

$$
t=\frac{(x-a)}{(b-a)}
$$

where the parameters $a$ and $b$ are the minimum and maximum values of the variable $x$, respectively; $p$ and $q$ are the distribution shape parameters and $B$ is the beta function defined by

$$
B(p, q)=\frac{\Gamma(p) \cdot \Gamma(q)}{\Gamma(p+q)}=\int_{0}^{1} t^{p-1}(1-t)^{q-1} d t
$$

The shape parameters $p$ and $q$ depend on whether the mode (most-likely value) is to the left or right of the midrange. They are determined using the method described in [6]. The resulted mean and standard deviation of the impact for each of the technologies are also summarized in Table 1.

The CDFs (eq. (2)) are calculated numerically. All three equations are implemented into the Fast Probability Integration (FPI) computer code [7], and are used to perform the probabilistic system analysis of the UEET technologies.

\section{System Analysis}

The approach taken in this effort is to combine thermodynamic cycle analysis using NPSS (Numerical Propulsion System Simulator) [8], engine weight estimation using WATE (Weight Analysis of Gas Turbine Engines) [9], aircraft mission sizing using FLOPS (Flight Optimization System) [10], and FPI. A schematic of the integrated approached is shown in Figure 1.

The computer code NPSS is used to calculate engine thrust, specific fuel consumption and LTO $\mathrm{NO}_{\mathrm{x}}$ emissions. The engine weight is calculated by the WATE code. The results from NPSS and WATE are used by FLOPS for performing airplane mission and sizing analyses, and ultimately calculates the fuel-burn based on a 5556-kilometers (3000 nautical miles) economic mission.

\section{Probabilistic Analysis}

All probabilistic analysis methods are approximate. Monte Carlo simulation, which is oftentimes referred to as the "exact" solution, is actually an approximate because a finite number of samples are always used. Thus, the nature of the approximation is one of "lack of data", which can be reduced by increasing the number of samples. However, for large-scale high fidelity problems, the inefficiency of Monte Carlo simulation renders it impractical for use. Many efficient methods have been developed to alleviate the need for Monte Carlo simulation. These methods include the first and second-order reliability method (FORM and SORM) [11], the advanced mean value family of methods (AMV) (12], and the response surface method (RSM) [13]. These methods replace the original deterministic model with a computationally efficient analytical model in order to speed up the analysis. 


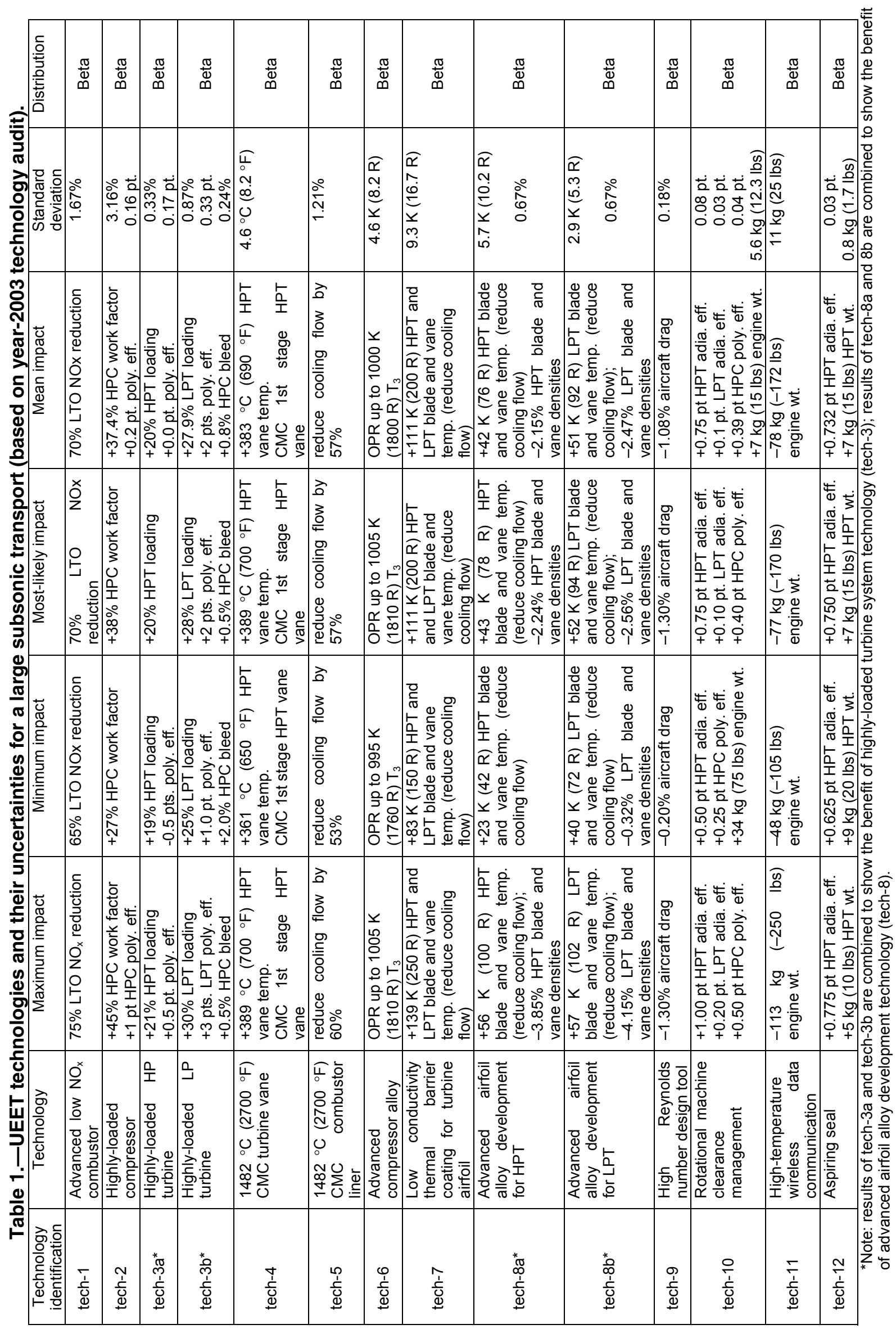




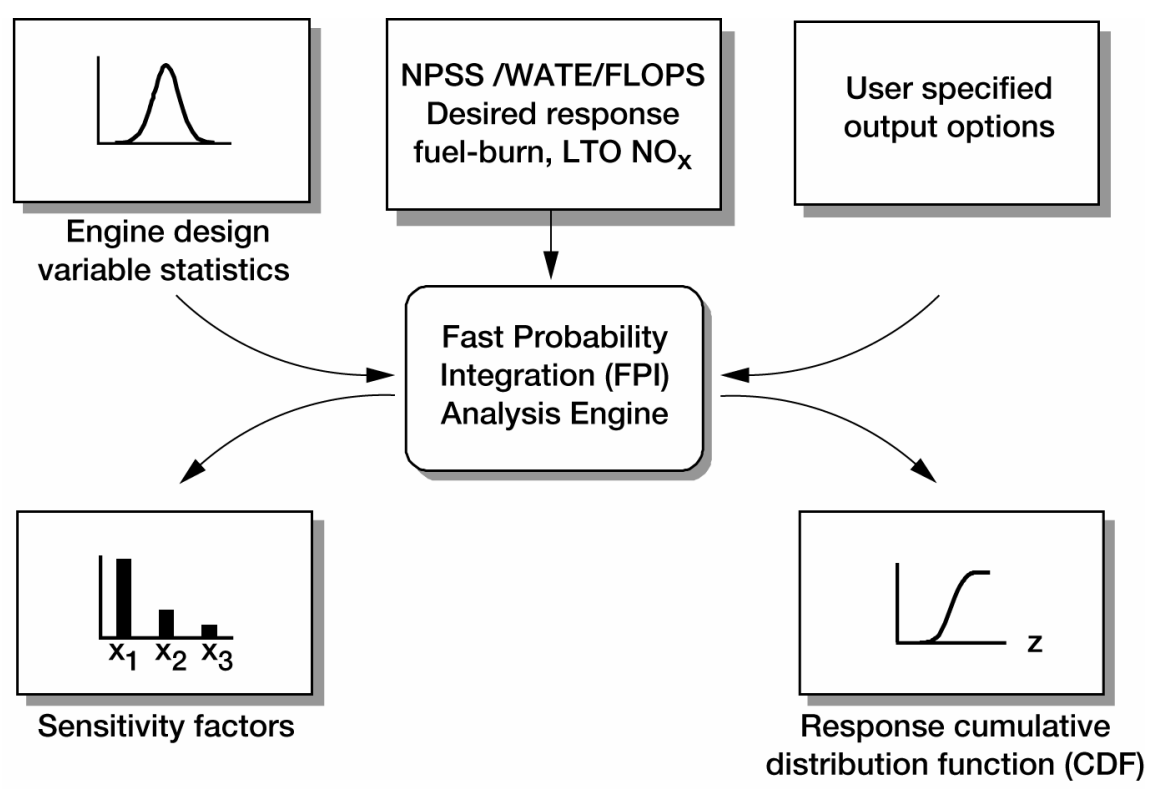

Figure 1.-Fast probability integration input/output schematic.

For the current assessment, an advanced first-order reliability method is used. This method, based on the mostprobable-point (MPP) concept, is one of the several methods in the FPI code. The code was developed under contract with NASA Glenn Research Center [14]. The role of FPI is to perform probabilistic analysis utilizing the results generated by NPSS, WATE, and FLOPS. The results are generated in the form of cumulative distribution functions (CDFs).

In addition, FPI is used to perform sensitivity analyses to rank the technologies in order of their impact on engine fuel burn and LTO $\mathrm{NO}_{\mathrm{x}}$ emissions. Sensitivity values could be + or - in nature. For the current assessment, a positive value indicates that the technology has positive impact on fuel burn (or LTO $\mathrm{NO}_{\mathrm{x}}$ ) reduction and a negative value has the opposite effect. Technology with the highest absolute sensitivity value is defined to be the most influential technology. The technology with the second highest absolute sensitivity value is the second most influential technology and so on. This approach ranks the technology in the order of their influence on engine performance (i.e., fuel burn or LTO $\mathrm{NO}_{x}$ reductions). The sensitivity information thus obtained from FPI is very useful from the design point of view. For example, engine performance reliability can be improved when uncertainties in the most influential technologies are reduced. Those technologies that do not have significant influences deterministically could nevertheless have strong influences on engine performance reliability if these technologies have huge uncertainties. Weak technology with large uncertainties may have probabilistic sensitivity factors more important than strong technologies with small uncertainties. Unlike deterministic analysis, sensitivity factors in probabilistic analysis are functions of both the deterministic sensitivity and the uncertainty (characterized by the standard deviation).

\section{LTO NOx Definition}

The correlation used for the current LTO $\mathrm{NO}_{\mathrm{x}}$ calculation is based on flame-tube tests $[15,16]$ and is defined as

$$
\begin{aligned}
& \mathrm{K}\left(\mathrm{P}_{\mathrm{t} 3}\right)^{0.5945} \exp \left[\left(\mathrm{T}_{\mathrm{t} 3}-459.67\right)(0.002867)\right] \times \\
& (\mathrm{FAR} / \text { delphi })^{1.6876}\left[\left(1-\mathrm{P}_{\mathrm{t} 4} / \mathrm{P}_{\mathrm{t} 3}\right) \times 100\right]^{-0.5651}
\end{aligned}
$$

where

K technology constant

$\mathrm{P}_{\mathrm{t} 3} \quad$ combustor inlet total pressure

$\mathrm{P}_{\mathrm{t} 4} \quad$ combustor exit total pressure

$\mathrm{T}_{\mathrm{t} 3} \quad$ combustor inlet total temperature

FAR fuel air ratio

delphi 1 - fraction of combustor inlet air used for liner cooling

\section{RESULTS AND DISCUSSION}

It is critical to assess the reliability of a new propulsion system because of inherent design uncertainties in the UEET technologies. The current assessment focuses on the technical aspect of engine performance, i.e., mission fuel-burn and LTO $\mathrm{NO}_{\mathrm{x}}$ emissions. The results are presented in the form of cumulative distribution functions (CDFs) and probabilistic sensitivities. A CDF gives a relation between a value up to certain magnitude of a response variable (fuel-burn or LTO NOx) and the probability of its occurrence. The results are relative to those of the current state-of-the-art 300-passenger airplane (baseline).

The results show that, the current portfolio of UEET technologies provides a greater than $99 \%$ confidence in meeting the UEET Program goal of $70 \%$ below the current LTO $\mathrm{NO}_{\mathrm{x}}$ rule, while the fuel-burn goal (15\% reduction) can be met with $97 \%$ confidence. The confidence levels indicate the risk of not meeting the UEET Program goals is very low for the fuel-burn and almost none for the LTO $\mathrm{NO}_{\mathrm{x}}$ emissions. The results are shown in Figures 2 and 3. 


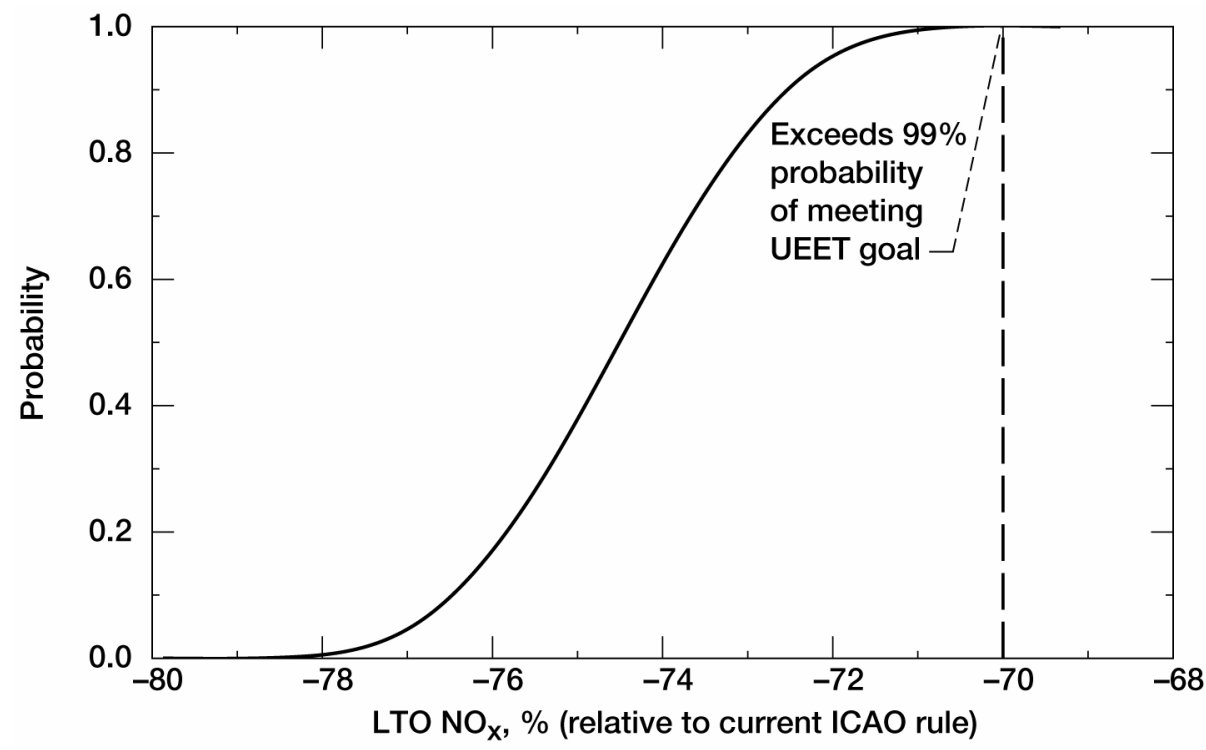

Figure 2.-Cumulative distribution function (CDF) of engine landing and takeoff (LTO) $\mathrm{NO}_{x}$ emissions.

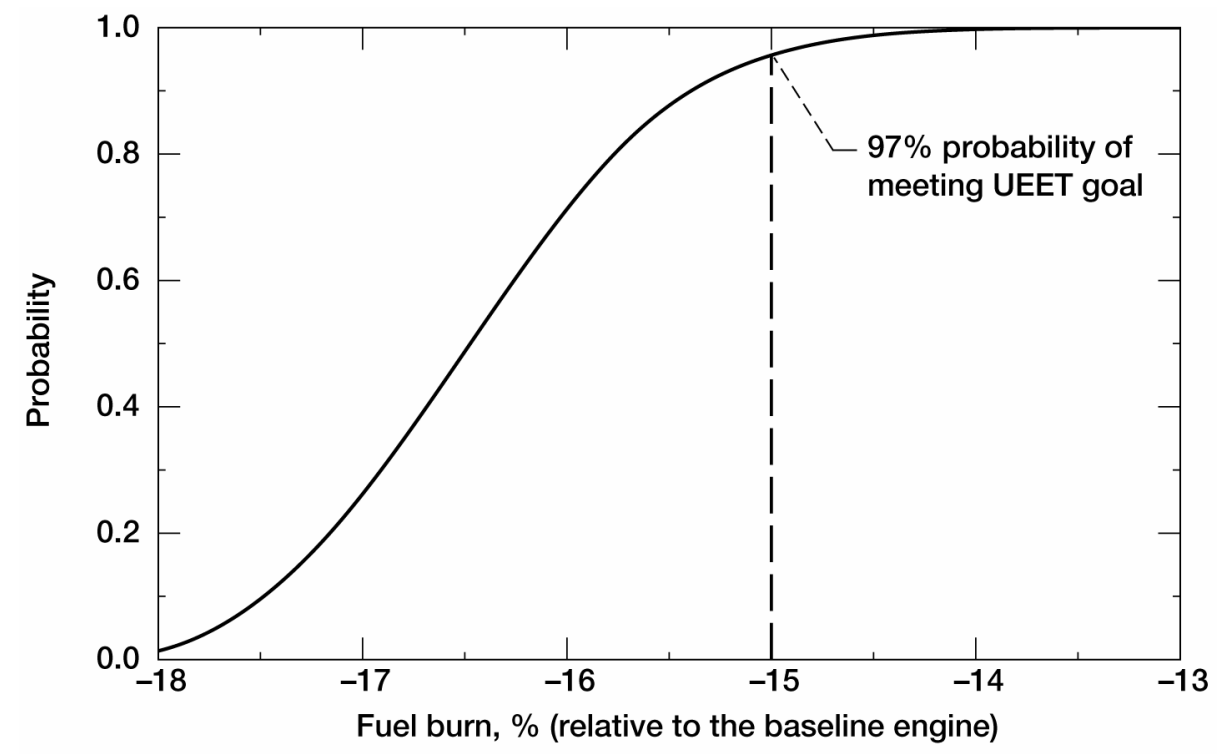

Figure 3.-Cumulative distribution function (CDF) of engine fuel burn.

\section{LTO NO Sensitivity}

The sensitivity of LTO $\mathrm{NO}_{x}$ to the twelve technologies, at 99\% probability level is shown in Figure 4. As expected, it shows that the advanced low-NO $O_{x}$ combustor (tech-1) has the dominant impact on the LTO $\mathrm{NO}_{\mathrm{x}}$ emissions. It implies that to reduce the LTO $\mathrm{NO}_{\mathrm{x}}$ emissions beyond the UEET goal, the biggest payoff is to focus on the combustor technology. Other technologies have minimal or no impact on the LTO $\mathrm{NO}_{\mathrm{x}}$ emissions. Among all the technologies, the Advanced compressor disk alloy (tech-6) is the only one that has a negative impact (though small) on the LTO $\mathrm{NO}_{\mathrm{x}}$. This technology enables the increase in the engine's overall pressure ratio which also increases the combustor inlet air temperature. That effect alone, assuming all other engine aspects are unchanged, will increase the LTO $\mathrm{NO}_{\mathrm{x}}$ emissions.

\section{Fuel Burn Sensitivity}

For the fuel-burn reduction, the sensitivity result at $97 \%$ is shown in Figure 5. It shows that the Highly loaded turbine systems (tech-3), Highly loaded compressor technology (tech2 ), and the high Reynolds number design tool for advanced configurations (tech-9) are the three most influential technologies. The influences of Advanced compressor disk alloy (tech-6), Low-conductivity thermal barrier coating for 


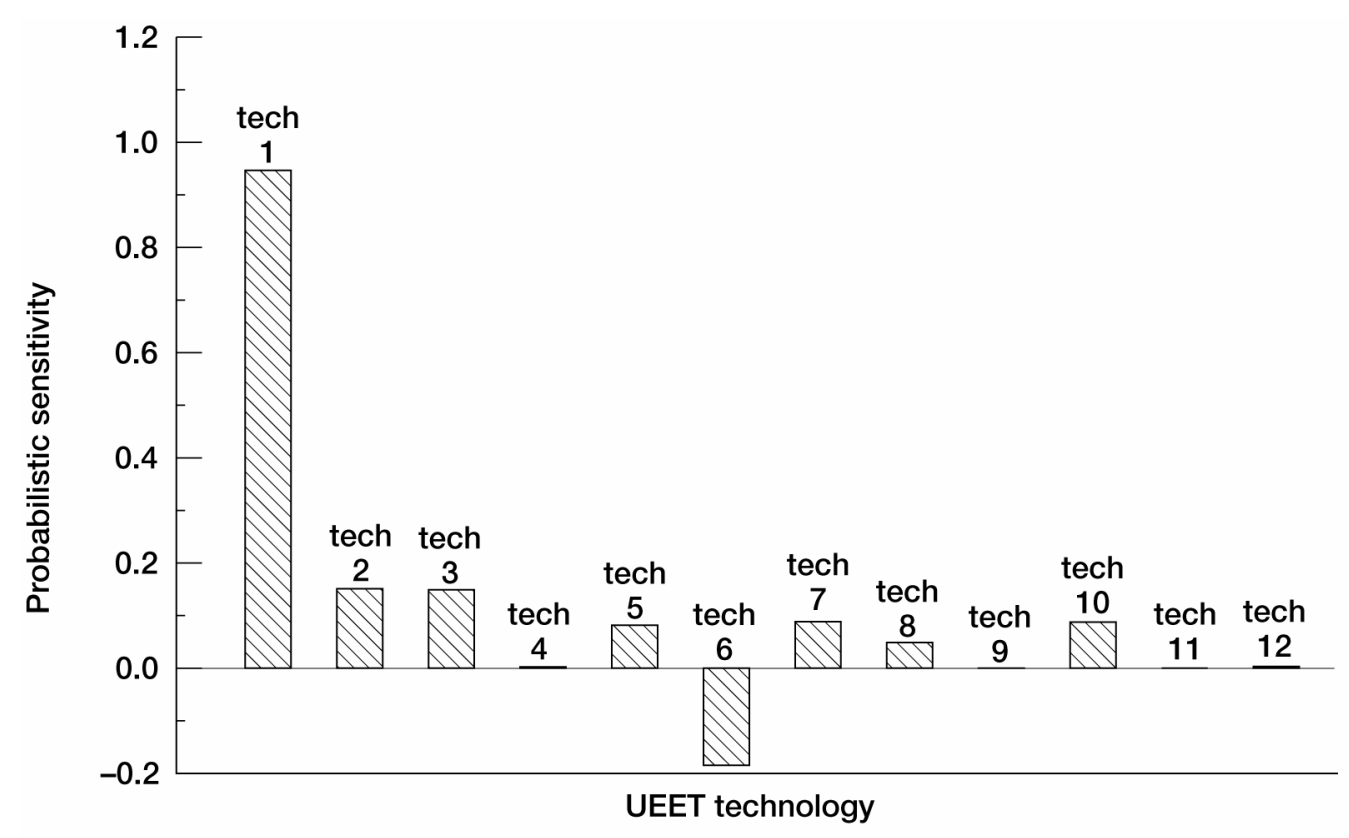

Figure 4.-Sensitivity of engine landing and takeoff (LTO) $\mathrm{NO}_{\mathrm{x}}$ emissions.

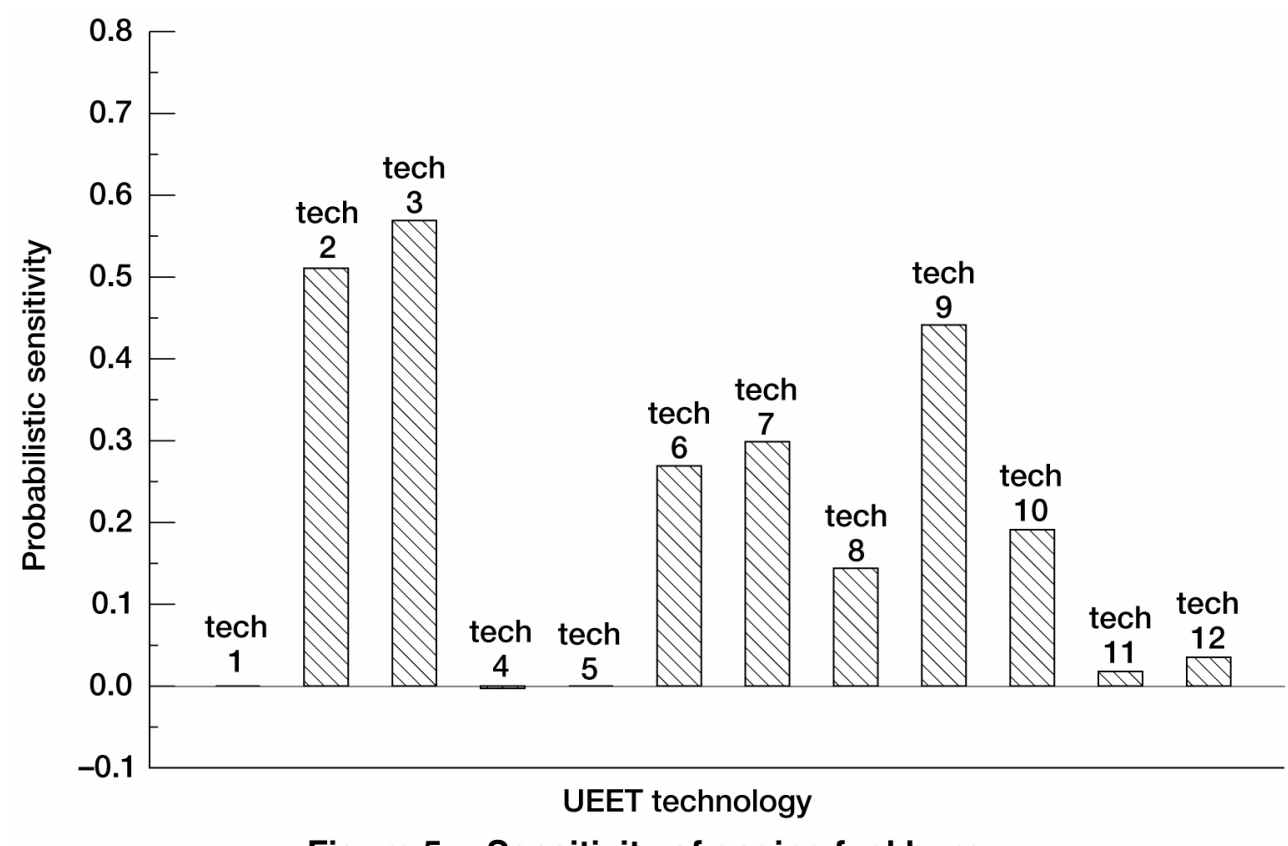

Figure 5.-Sensitivity of engine fuel burn.

turbine airfoils (tech-7), and Rotating machinery clearance management (tech-10) are moderate. Other technologies have minimal or no impact on the fuel-burn reduction.

Among these six top-ranking technologies, tech-6 and tech-7 are material technologies. It is noted that tech-7 and tech-8 (Advanced airfoil alloy development) provide the same type of benefit, enable the amount of turbine cooling to be reduced. However, according to the expert opinion (see Table 1), tech-7 enables more cooling flow reduction. As a result, tech-7 has a much higher impact on the fuel burn. Another coolant-reduction technology, tech-4 (1482 ${ }^{\circ} \mathrm{C}$ CMC turbine vane), has insignificant impact on the fuel burn, relative to tech-7 and tech-8. This is because tech-4's coolant reduction comes primarily from the first turbine vane (i.e., nonchargeable cooling) which is not as advantageous as a reduction in chargeable cooling (as for tech-7 and tech-8). Overall, the current results show that advanced materials are the key enablers for meeting the UEET Program goals.

The results also implies that an alternative approach to satisfy the UEET Program goals is to focus on the development of the six largest fuel-burn reduction technologies plus, the Advanced low-NO $\mathrm{O}_{x}$ combustor (tech-1). By reducing the uncertainties of these six technologies by $25 \%$, and by keeping the uncertainty of tech-1 the same, while assuming other 
technologies provide only minimum impacts/benefits (from the 3-point estimates), the probability of meeting the UEET fuelburn goal exceeds $99 \%$, as shown in Figure 6 . In fact, this technology portfolio enables a greater than $99 \%$ probability of exceeding the UEET fuel-burn goal, with $16.5 \%$ fuel-burn reduction relative to the baseline. This is achieved without sacrificing the LTO $\mathrm{NO}_{\mathrm{x}}$ goal, as shown in Figure 7.
It is noted that, in a recent independent review of NASA's Aeronautics Technology Programs performed by the National Research Council, these seven technologies, together with tech8 (Advanced airfoil alloy development) have been rated either world-class or exceptionally good technologies [17].

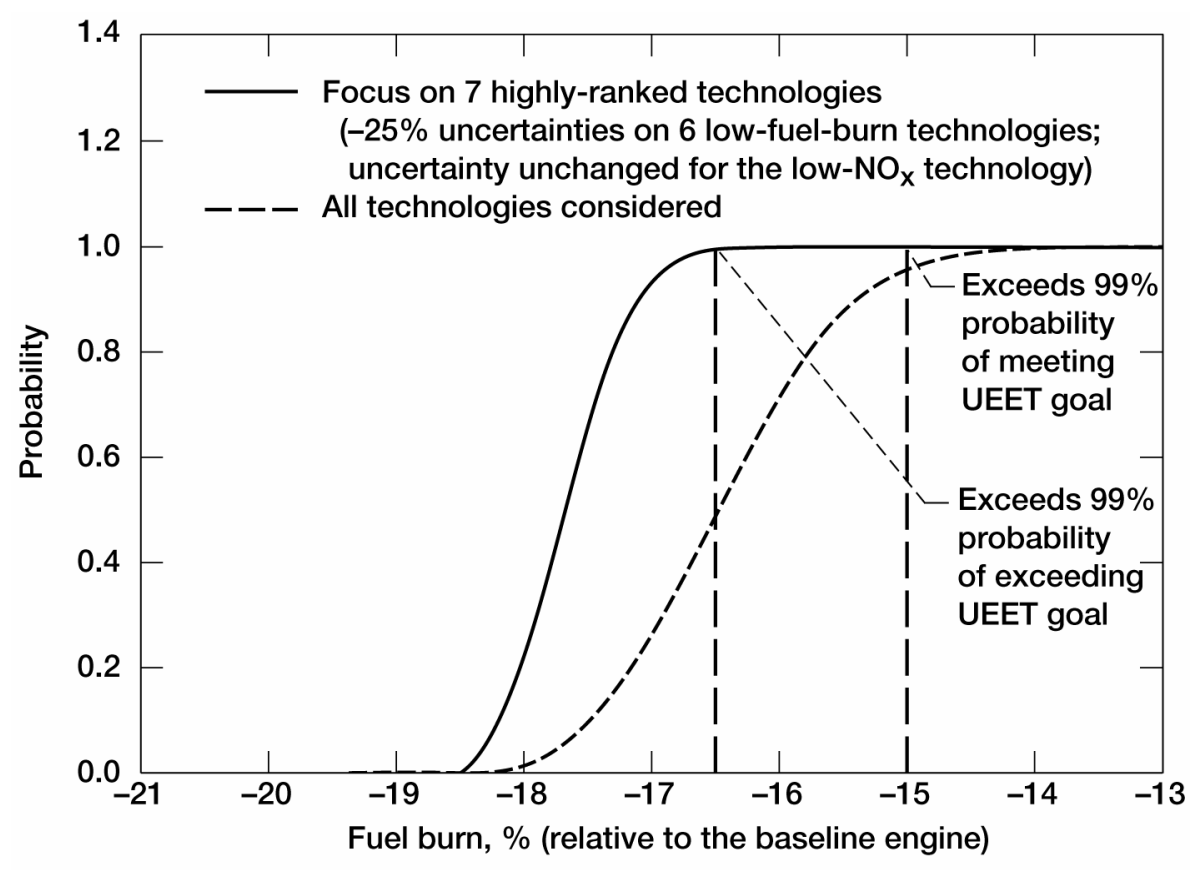

Figure 6.-Impact of uncertainty-reduction on engine fuel burn.

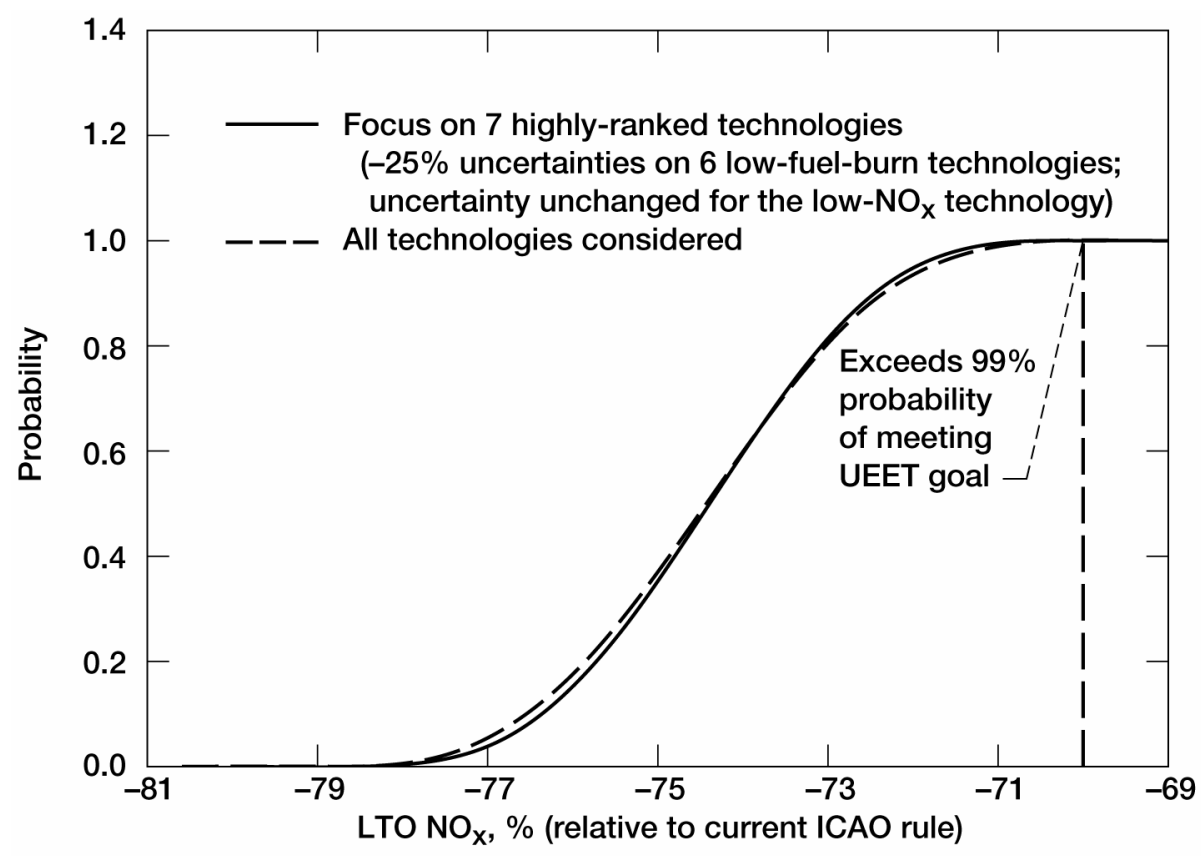

Figure 7.-Impact of uncertainty-reduction on landing and takeoff (LTO) $\mathrm{NO}_{x}$ emissions. 


\section{CONCLUSIONS}

Based on the current assessment results, the following conclusions are made:

(1) A large subsonic aircraft equipped with the UEET technologies has a very high probability of meeting the UEET Program goals for fuel burn and LTO $\mathrm{NO}_{x}$ reductions, over $96 \%$.

(2) The top-seven UEET technologies for fuel-burn or $\mathrm{CO}_{2}$ reduction are:

a. Highly loaded turbine system

b. Highly loaded compressor

c. High Reynolds number design tool for advanced configuration

d. Low conductivity ceramic thermal barrier coating for turbine airfoils

e. Advanced compressor disk alloy

f. Rotating machinery clearance management

g. Advanced airfoil alloy development

(3) A technology that enables significant non-chargeable coolant reduction (such as $1482{ }^{\circ} \mathrm{C}$ CMC turbine vane) is not as advantageous as those that enable significant chargeable coolant reduction (such as Low thermal conductivity ceramic TBC for turbine airfoils and Advanced airfoil alloy development), for fuel burn reduction.

(4) The Advanced low $N O_{x}$ combustor technology has the most and dominant impact on the LTO $\mathrm{NO}_{\mathrm{x}}$ reductions.

(5) Advanced materials are key enablers for meeting the UEET Program goals.

(6) The UEET Program goals can be exceeded with high probability by focusing on the top-ranking technologies and reducing their uncertainties.

(7) An effective expert opinion elicitation process, or technology audit, is crucial for performing probabilistic assessment. A process that includes both the experts from NASA and the engine industry will ensure the audited data are indeed reasonable representation of each of the technologies' potential.

(8) The probabilistic approach provides a more realistic and systematic way to assess advanced propulsion technologies, because it accounts for their inherent uncertainties.

\section{ACKNOWLEDGMENTS}

The authors wish to acknowledge the efforts of Dr. Michelle Kirby of Georgia Institute of Technology in conducting the technology audit and providing the audit information used in this study.

\section{REFERENCES}

[1] Millett, Stephan M. and Honton, Edward J., "A Manager's Guide to Technology Forecasting and Strategic Analysis Methods," Battelle Press, 1991.

[2] Hudak, David G., "Adjusting Triangular Distribution for Judgmental Bias,” Risk Analysis: 14, no. 6, pp. 1025-1031, December 1994.
[3] Kirby, M.R. and Mavris, D.N., "Forecasting Technology Uncertainty in Preliminary Aircraft Design," SAE Paper No. 1999-01-5631.

[4] Sackman, H., "Delphi Assessment: Expert Opinion, Forecasting, and Group Process." Rand report R-1283-PR, Rand Corporation, April 1974. Santa Monica, CA.

[5] Kirby, M.R. and Mavris, D.N., "Final Report - UEET Program Metrics Assessment Implementation, Option 2A Phase II," NASA Contract NAS3-00179, NASA Glenn Research Center, February 18, 2003.

[6] Holland, Frederic A., "A Simple Method for Estimating the Parameters of the Beta Distribution Applied to Modeling Uncertainty in Gas Turbine Inlet Temperature," ASME Turbo Expo Paper GT-2002-30295.

[7] Southwest Research Institute: FPI User's and Theoretical Manual, San Antonio, TX, 1995.

[8] NASA-Industry Cooperative Effort: "Numerical Propulsion System Simulation User Guide and Reference," Software Release NPSS 1.5.0, May 7, 2002.

[9] Onat, E. and Klees, G.W., "A Method to Estimate Weight and Dimensions of Large and Small Gas Turbine Engines," NASA CR-159481, 1979.

[10] McCullers, L.A., "Flight Optimization System User's Guide, Version 5.85," NASA Langley Research Center, 1998.

[11] Madsen, H.O., Krenk, S., and Lind, N.C., "Methods of Structural Safety," Prentice-Hall, Inc., New Jersey, 1986.

[12] Wu, Y.-T., Millwater, H.R., and Cruse, T.A., "Advanced Probabilistic Structural Analysis Methods for Implicit Performance Functions," AIAA Journal, 28, no. 9, September 1990.

[13] Faravelli, L., "Response Surface Approach for Reliability Analysis," Journal of Engineering Mechanics, 115, no. 12, 1989.

[14] Southwest Research Institute, "Probabilistic Structural Analysis Methods (PSAM) for Select Space Propulsion System Components," Final Report NASA Contract NAS3-24389, NASA Glenn Research Center, 1995.

[15] Tacina, R., Mao, C., and Wey, C., "Experimental Investigation of a Multiplex Fuel Injector Module with Discrete Jet Swirlers for Low Emission Combustors," AIAA-20040185 .

[16] Wey, C., "A High Pressure and High Temperature $\mathrm{NO}_{\mathrm{x}}$ Correlation," paper to be published.

[17] National Research Council, "An Assessment of NASA's Aeronautics Technology Programs," The National Academies Press, 2003. 